\title{
The Microbial Diversity of Fairly Used Wears Sold In a Lagos Market, Nigeria
}

\author{
F. A.Olajubu; V. T. Folorunso, O. Olojede. \\ Department of Microbiology, Adekunle Ajasin University, Akungba-Akoko, Nigeria
}

\begin{abstract}
:
Background: Strong desire for foreign wears and the global economic recession favour the importation and use of fairly used clothes without giving consideration to any attending health implication. This study examined the level of microbial contamination in some fairly used clothes and the effect of washing them with different detergents and disinfectants on the microbial load of these wears.

Materials and Method: Second hand clothes such as bed sheets, towels, children wears, adult wears and panties were bought from Katangua Flea Market in Lagos, Nigeria, between August and September, 2014. Isolation of contaminating microbes was carried out using Culture and Plate Count methods. Isolates were identified through morphology and appropriate biochemical methods. Susceptibility test was done on each of the bacteria isolates.

Results: The most frequently isolated organism was Staphylococcus aureus. Other microorganisms isolated are Pseudomonas sp, Coagulase-negative Staphylococci, Bacillus sp, Aspergillus flavus, Rhodotorula sp, Candida $s p$, Mucor sp, Geotrichum sp, Saccharomyces sp and Penicillium sp. Towels had the highest bacteria count $\left(12 \times 10^{2} \mathrm{cfu} / \mathrm{mm}^{2}\right)$ while the adult wears had the lowest count $\left(2.3 \times 10^{2} \mathrm{cfu} / \mathrm{mm}^{2}\right)$. Pseudomonas aeruginosa was totally resistant to five of the antibiotics examined, however Staphylococcus aureus isolates were susceptible to Quinolones and Cephalosporins. The most significant reduction in the microbial load of the wears was observed after washing with Hypo detergent thereby becoming the most effective among the detergents used.

Conclusion: It became obvious that second hand clothes are potential carriers of pathogens for skin and other infections and therefore should be properly washed before use in instances where they cannot be totally avoided.
\end{abstract}

Key Words: Used wears, plate count, detergents, Staphylococcus aureus, Penicillium sp.

\section{Introduction}

Fairly used clothes in Nigeria are known as "Okrika" and are clothing materials like shirts, trousers, towels, socks, panties, pillow cases, curtains and bed sheets imported from United States of America, United Kingdom, Asia, Germany and Netherlands after been used for a while by the initial buyer (Agbulu et al., 2015). They are packed in bundles known as bales during importation. Nigerians desire for foreign goods (including wears) increases daily. Though the wears are cheaper, usually the driving force is the quality of the products which are adjudged better than the new ones. These are purchased without giving consideration to any attending health implications. Clothes have the potential, just as any other hand contact site, to be a component in the chain of infection transmission during normal daily activities (Malnick et al., 2008). All forms of skin infections can be caused by wearing contaminated second hand cloths. Bloomfield et al., (2011) showed that clothes have the capacity to retain bacteria, fungi and viruses for varied lengths of time. The need for regular monitoring of fairly used cloths is supported by data generated from previous studies. Staphylococcus aureus and Enterococci have been isolated from materials commonly worn by patients and health care workers (Neely and Maley, 2000) Similarly, Pilonetto et al., (2004) and Neely and Orloff (2001) detected Staphylococcus aureus, Klebsiella pneumonia, Acinetobacter baumani, Candida sp, Aspergillus sp, Mucor sp. and Fusarium sp from fabrics which were associated with nosocomial infections. Agbulu et al., (2015) also demonstrated the presence of some bacteria and fungi of medical importance from fairly used clothes. Disinfection has been shown to reduce the number of pathogenic microbes in fairly used clothes (Gerald and Russel, 1999). Some conscientious buyers often wash these wears with detergents and water while others wear them directly as new cloths. The potential for spread of pathogens to clothing from infected sources (people, foods, domestic animals) is relatively high as reviewed by Bloomfield et al., (2011). It is estimated that around 106 skin squames containing viable organisms are shed daily from normal skin (Wilkoff et al., 2006). 'Okrika' as is fondly called, is highly patronized by Nigerians and yet, there are very little information on the attending health implications and what to do so as to reduce it. This study therefore examined the level of microbial contamination in some fairly used clothes sold in Katangua Flea market in Lagos and the effect of washing the clothing materials with commonly available detergents on the microbial loads of these clothes. 


\section{Collection of samples}

\section{Materials And Methods}

Five categories of fairly used cloth samples (towels, bed sheets, adult wears, children wears and panties) were procured between August and November, 2014 from Katangua market, a popular market for the selling of fairly used clothes, located in Lagos, Nigeria. The five categories of clothes were gotten in triplicates and labelled accordingly. The samples were then placed in sterile polythene bags and brought to the Microbiology Laboratory of Adekunle Ajasin University, Akungba-Akoko for analysis. Standard methods were used in the isolation and identification of the contaminating microorganisms.

\section{Isolation of Bacteria}

A $10 \times 10 \mathrm{~cm}$ area of the cloth samples was swabbed using sterile cotton swab immersed in $5 \mathrm{mls}$ of sterile peptone water. The swabs were then sub-cultured on Mannitol Salt agar, Blood agar, Plate Count agar and MacConkey agar. The plates were examined after incubation at $37^{\circ} \mathrm{C}$ for 24 hours. The growth colonies were identified using standard microbiological techniques. Total microbial counts were expressed as colonyforming units per $\mathrm{cm}^{2}\left(\mathrm{cfu} / \mathrm{cm}^{2}\right)$ (Cheesbrough, 2006)

\section{Isolation of Fungi}

An area of $100 \mathrm{~cm}^{2}$ of the cloth samples was swabbed using sterile cotton swab moistened with sterile peptone water. The swabs were streaked on Saboruad Dextrose agar, Potato Dextrose agar and Rose Sporulating Medium (RSM). The plates were incubated at $28^{0} \mathrm{C}$ for 3-5 days. Identification of isolates were done by Lactophenol cotton blue staining and by the use of standard Mycology Atlas (Winn et al., 2006)

\section{Germ Tube Test:}

Few colonies of suspected yeast growth were introduced into human serum and incubated for 30 minutes. The preparation was observed under the microscope for budding yeast. Presence of bud confirmed Candida albican.

\section{Isolation of dermatophytes}

The cloth samples were swabbed with sterile swab sticks and inoculated on Dermatophyte Test Medium (DTM) which is a specialized agar for isolation of dermatophytes. After 5 days of incubation, dermatophyte fungus, which utilizes nitrogenous material for metabolism, produces alkaline by-products thereby imparting a red color change on the medium. Further identifications were done with Lactophenol cotton blue staining and microscopic examination.

\section{Endospore staining test}

The Endospore stain is a differential stain used to visualize bacterial endospores. The organisms to be tested for endospore were smeared on a clean grease free glass slide. The smears were heat fixed. The smeared slides were saturated with malachite green and gentle heat. The slides were counterstained with $0.5 \%$ safranin, washed, blotted and examined under the microscope for vegetative cells which appear red while the spores appear green.

\section{Susceptibility test}

Standard inoculums of the test organisms were prepared and streaked on already prepared Muller Hinton agar with the aid of sterile swab stick. Antibiotic discs of known concentrations were placed on the media and incubated at $37^{\circ} \mathrm{C}$ for 24 hours. The susceptibility pattern of the test isolates were checked for after the incubation period. (NCCLS, 1990)

\section{Bacterial load determination of clothes samples after washing with detergents.}

Cloth samples of the same size for pre-washed microbial load determination were cut, washed with three different detergents (Omo, Ariel and Hypo). Each of the swatches were washed in the beakers for 1 minute and afterwards, rinsed and dried in a sterilized incubator set at $37^{\circ} \mathrm{C}$. Upon drying, the swatches were packed into sterile polythene bags and labelled. Samples were collected into separate test tubes containing peptone water. $0.1 \mathrm{ml}$. The contents of the test tubes was dispensed into Petri dishes. Twenty milliliters $(20 \mathrm{mls})$ of molten Plate Count Agar was poured into each Petri dish and the contents were swirled to mix properly. The plates were incubated at $37^{0} \mathrm{C}$ for 24 hours. After 24 hours of incubation, the counts and further identification of the colonies were carried out. 


\section{Results}

Of the different cloth types examined, bedsheet had the highest bacterial count $\left(40 \times 10^{2} \mathrm{cfu} / \mathrm{cm}^{2}\right)$ while towel had the least count of $11 \times 10^{2} \mathrm{cfu} / \mathrm{cm}^{2}$. The counts for children wear, adult wear and panties ranged between 18 and $20 \times 10^{2} \mathrm{cfu} / \mathrm{cm}^{2}$. The results obtained after each of the cloth types were washed showed that, Omo had better activity on bacteria from bed sheet and adult wears, effect of Hypo was much felt on towels while Ariel demonstrated the weakest reduction potency as shown in Figure 1.

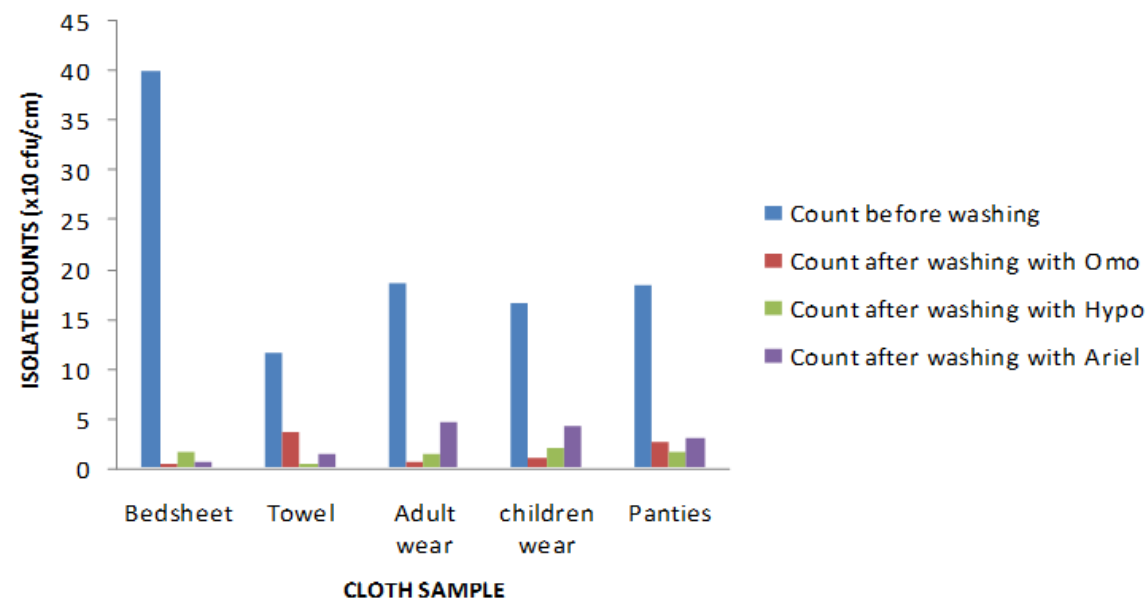

Figure 1: Average colony count before and after washing with detergents.

Bacterial frequency of isolation is shown in Table 1. Staphylococcus aureus was the most frequently isolated bacterium (60.7\%) while Pseudomonas aeruginosa was isolated in only $2(7.1 \%)$ of the cloth samples. Other isolated bacteria are Coagulase-negative Staphylococci (14.3\%) and Bacillus sp (17.9\%).

Table 1: Frequency of bacteria isolates from fairly used cloth samples

\begin{tabular}{lcc}
\hline Organisms & Number isolated & \% occurrence \\
Staphylococcus aureus & 17 & 60.7 \\
Coagulase-negative Staphylococci & 4 & 14.3 \\
Bacillus sp & 5 & 17.9 \\
Pseudomonas aeruginosa & 2 & 7.1 \\
Total & 28 & 100
\end{tabular}

Four species of Aspergillus which accounted for 34.3\% of the total fungi isolates were recorded in this study. Mucor sp and Scopulariopsis brevicalis were isolated in 5(14.3\%) and 4(11.4\%) cloth samples respectively. Gonytrichum sp was isolated from 1(2.9\%) sample as clearly listed in Table 2.

Table 2: Frequency of Fungi isolates from fairly used Cloth samples

\begin{tabular}{|c|c|c|}
\hline Fungi species & Number Isolated & \% Occurrence \\
\hline Saccharomyces sp & 2 & 5.7 \\
\hline Rhodotorula sp & 3 & 8.6 \\
\hline Candida sp. & 6 & 17.1 \\
\hline Aspergillus ochraceus & 1 & 2.9 \\
\hline Aspergillus wentii & 1 & 2.9 \\
\hline Aspergillus niger & 6 & 17.1 \\
\hline Aspergillus flavus & 4 & 11.4 \\
\hline Peniccilium sp & 2 & 5.7 \\
\hline Mucor sp & 5 & 14.3 \\
\hline Scopulariopsis brevicalis & 4 & 11.4 \\
\hline Gonytrichum sp & 1 & 2.9 \\
\hline Total & 35 & 100 \\
\hline
\end{tabular}

A comparison of microbial load on new cloths sold in the same location showed a marked difference. 
No bacteria was isolated from new adult wears compared with 20 isolated from fairly used, the highest number of bacteria (5) was isolated from towels as against thirteen (13) isolated from fairly used towel. Similar pattern was recorded for fungi isolates. Only 1 fungus was isolated from new towels compared with 33 from fairly used samples, 2 from new panties as against 42 isolated from fairly used panties. These are shown in Table 3.

Table 3: Comparison of total microbial counts of New wares with Fairly used cloth samples $\left(\mathrm{x} 10 \mathrm{cfu} / \mathrm{cm}^{2}\right)$

Wears

Bacteria

$\begin{array}{lccc} & \text { Fairly } & \text { New } & \text { Diff.(\%) } \\ & \text { Used } & & \\ \text { Towel } & 13 & 5 & 8(61.5) \\ \text { Bedsheet } & 40 & 3 & 37(92.5) \\ \text { Panties } & 20 & 4 & 16(80.0) \\ \text { Adult Wears } & 20 & - & 20(100) \\ \text { Children Wears } & 18 & 2 & 16(88.9)\end{array}$

$\begin{array}{cr}\text { Fairly } & \text { New } \\ \text { Used } & 1 \\ 33 & 2 \\ 8 & 2 \\ 42 & 3 \\ 8 & 6\end{array}$

Diff. $(\%)$

32(97.0)

$6(75.0)$

$40(95.2)$

$5(62.5)$

$15(71.4)$

The susceptibility pattern of the bacteria isolates are presented in Table 4. Most isolates of S. aureus are sensitive to Cotrimoxazole (70.6\%), Gentamycin (88.2\%), Cephalosporin (88.2\%) Ciprofloxacin (100\%) and Erythromycin (70.6\%) but, performed poorly against Ampicillin (11.8\%) and Augmentin (17.7\%). CoNS had $100 \%$ sensitivity to Gentamycin, Cephalosporin, Ciprofloxacin and erythromycin, but $25 \%$ to Ampicillin, Amoxicillin and Augmentin. Ciprofloxacin and Cephalosporin were the most efficient antibiotics against Bacillus sp isolates. Pseudomonas sp showed complete resistance to 5 of the antibiotics but susceptible to Augmentin and Ciprofloxacin.

Table 4: Antimicrobial sensitivity pattern of the bacteria isolates

\begin{tabular}{|c|c|c|c|c|}
\hline Antimicrobials & $\begin{array}{l}\text { S. aureus }(\%) \\
\mathrm{n}=17\end{array}$ & $\begin{array}{l}\text { Organisms } \\
\text { CoNS }(\%) \\
n=4\end{array}$ & $\begin{array}{c}\text { Bacillus sp (\%) } \\
\mathrm{n}=5\end{array}$ & $\begin{array}{c}\text { Ps. aeruginosa (\%) } \\
\mathrm{n}=2\end{array}$ \\
\hline COT & $12(70.6)$ & $2(50.0)$ & $3(60.0)$ & $0(0.0)$ \\
\hline CHL & $5(29.4)$ & $2(50.0)$ & $1(20.0)$ & $0(0.0)$ \\
\hline GEN & $15(88.2)$ & $4(100.0)$ & $3(60.0)$ & $1(50.0)$ \\
\hline AUG & $3(17.7)$ & $1(25.0)$ & $2(40.0)$ & $2(100.0)$ \\
\hline AMX & $3(17.7)$ & $1(25.0)$ & $2(40.0)$ & $1(50.0)$ \\
\hline CEP & $15(88.2)$ & $4(100.0)$ & $5(100.0)$ & $1(50.0)$ \\
\hline CIP & $17(100.0)$ & $4(100.0)$ & $5(100.0)$ & $2(100.0)$ \\
\hline AMP & $2(11.8)$ & $1(25.0)$ & $2(40.0)$ & $0(0.0)$ \\
\hline ERY & $12(70.6)$ & $4(100.0)$ & $1(20.0)$ & $0(0.0)$ \\
\hline STR & $7(41.2)$ & $2(50.0)$ & $1(20.0)$ & $0(0.0)$ \\
\hline
\end{tabular}

Key: COT- cotrimoxazole; CHL- chloramphenicol; GEN- gentamycin; AUG- augmentin; AMX- amoxicillin; CEP- cephalexin; CIP- ciprofloxacin; AMP- ampicillin; ERY- erythromycin; STR- streptomycin

\section{Discussion}

All the five samples of fairly used cloth examined in this study showed varying degree of contamination with bacteria and fungi. The level of patronage given to these cloths by all in the society makes it a matter of public health importance. Though, there are no data to show the link between wearing of fairly used cloths and any infectious disease or disease outbreaks, but the organisms isolated have been incriminated in one disease condition or the order. Bed sheet, which is one of the commonly purchased fairly used cloths, had the highest bacteria count from this study. This brings to bear, the need to know the source of these fairly used cloths. Shiomori et al., (2002) and Trillis et al., (2008) demonstrated the colonization of bed sheets and curtains in a Japanese hospital with pathogens like Methicillin resistant Staphylococcus aureus (MRSA), Clostridium difficile and Vancomycin - resistant Enterococci (VRE). If these bed sheets get to the markets as fairly used cloths, the lives of buyers /users become endangered. The varied efficacy of the different detergents used for different cloth types recorded in this study provides a guide as to which detergent can be used with a particular wear. For bed sheets and adult wears, Omo performed better than other detergents, the reason for this might be in the components of the detergents, texture of the cloth materials and the primary level of contamination. Towels with heavier textures are better re-washed with Hypo whereas the efficacies of the detergents against children wear and panties are relatively similar. However, there was a general reduction in the microbial load with the use of the detergents, this agrees with the studies of Muthaini et al., (2010) in Kenya, where he used 
grade 2 laundry bar soap. Staphylococcus aureus $(60.7 \%)$ was the most commonly isolated bacterium from the examined fairly used cloth samples. This organism has also been isolated from previous studies by Mathaini et al., (2010) Sattler and Armando, (2004) and Gaspard et al., (2009). S. aureus has been incriminated largely in nosocomial infections with multiple drug resistant strains, staphylococcal food poising and skin infections such as boils, styes and furuncules (Khadri and Alzohairy). This organism is also associated with pneumonia, Urinary tract infections, bacteremia and endocarditis (Tekalign and Bacha, 2013; Fowler et al., 2006; Fekety, 1964). S. aureus isolation from these cloth samples no doubt is of public health concern. Bacillus sp was the principal bacterium isolated by Agbulu et al (2015) and was also isolated from this study. Bacillus sp is not known as human pathogen but can cause food poising. Its isolation might be related to the fact that Bacillus sp generally can withstand harsh environmental conditions like heat, desiccation, toxic chemicals and ultraviolet irradiation because of its ability to form endospores by which it can remain dormant for years. (Nester et al., 2004; Agbulu et al.,2015). Before now, Coagulase-negative Staphylococci (CoNS) were known to be non-pathogenic, hence its isolation would not have been so important. Recent studies has shown the involvement of CoNS in disease conditions being isolated from cases of bacteremia, meningitis and Urinary tract infection (Koksal et al., 2009; Drozenora and Petras, 2000; Huang et al., 2009) It has also become a major cause of nosocomial infections (Khadri and Alzohairy, 2010; Koksal et al., 2009). Hence, its isolation from fairly used cloth samples call for concern. Pseudomonas aeruginosa isolated from this study has been documented in serious wound infections, many strains of which are multidrug resistant (Nkang et al., 2009). In this study, Candida sp was isolated in $17.1 \%$ of the cloth samples, this is in agreement with the work of Agbulu et al., (2015). Candida is associated with onchomycosis, nosocomial candidaemia, gastro enteritis, skin and oral thrush, vagina infections especially among diabetics, pregnant women and immunocompromised patients ( Kothavade et al., 2014). Aspergillus spp are causes of pulmonary and corneal infections. They are equally isolated from this study. Rhodotorula sp which was also isolated from curtains (Wirth et al., 2012) is a major cause of meningitis and other systemic mycosis. Fungi tend to survive longer than bacteria on fabrics hence they are constantly present on fairly used cloth materials (Muthaini, 2010). A comparison of the fairly used cloth with new cloth materials from the same location showed marked difference in their microbial load. Though the new cloths were not all sterile but had far lesser microbial counts. The few counts might be due to factors like customers touching to feel texture and quality, environmental pollution, sewing and packaging system or seller's carrier status. It is therefore advisable to display new wears in a covered or glass-cased showrooms as against the open display commonly encountered to attract buyers. The susceptibility pattern of the isolates showed that multiple resistance was demonstrated by Pseudomonas aeruginosa. This was contrary to the work of Nkang et al., (2009) who reported only $18.2 \%$ resistance for Pseudomonas aeruginosa. Many studies show high resistance of $S$. aureus to Erythromycin, Tetracycline and Ciprofloxacin (Huang et al., 2003; Ertek et al., 2002). This does not agree with the findings of this present study where high susceptibility ratio was demonstrated against Erythromycin and Ciprofloxacin. The noticed contrast might be source of contamination/infection related. It is generally believed that hospital isolates are more resistant than community acquired strains.

\section{Conclusion}

Diverse potential pathogens were isolated from the second hand clothes with bed sheet and panties been the one with the highest microbial count for bacteria and fungi respectively. These isolated pathogens are also incriminated in life threatening diseases. Though the use of detergents in re-washing the fairly used wears reduced the microbial load, it never removed them totally. The flare for fairly used clothes because of the assumption that they are cheaper and of better quality than new ones will have to be weighed carefully in view of the likely attending health implications.

\section{References}

[1]. Agbulu, C.O., Gberikon, G.M., and Ajine, B.O. 2015 Isolation and characterization of microorganisms associated with second hand female undergarments and children wear sold in Makurdi Metropolis. Int. J. Curr. Microbiol. App. Sci. 4(1): 716-724

[2]. Bloomfield, S. F. Exner M. Signorelli C., Nath, K.J and Scott, A.E. 2011. The infection risks associated with clothing and household linen in home and everyday life settings and the role of laundary. International Scientific forum on home hygiene. 1: 147

[3]. Cheesbrough, M. 2006 District Laboratory Practice in Tropical Countries Cambridge University Press. Pp434

[4]. Drozenova, J. and Petras, P. 2000 Characteristics of Coagulase-negative staphylococci isolated from hemocultures. Epidemiol. Microbiol. Imunol. 49: 51-58

[5]. Ertek, M., Yazgi, H. and Erol, S. 2002 Demonstration of in vitro antagonism between fusidic acid and quinolones. J Int. Med. Res. 30:525-8

[6]. Fekety,F.R. 1964 The epidemiology and prevention of staphylococcal infection. Medicine Baltimore. 43: 593

[7]. Fowler, V.G., Helen M.H.S., Boucher, W., Corey, R. G. and Abrutyn, E. 2006 Daptomycin versus standard therapy for bacteremia and Endocarditis caused by Staphylococcus aureus. The new England Journal of Medicine. 355 (7): 1812-17

[8]. Gaspard P, Eschbach E, Gunther D, Gayet S, Bertrand X and Talon D. 2009 Methicillin resistant Staphylococcus aureus contamination of healthcare workers' uniforms in long-term care facilities. Journal of Hospital Infection.71:170-5.

[9]. Gerald, M. and Russell, A. D. 1999. Antiseptics and Disinfectants: Activity, Action, and Resistance Clinical Microbiology Reviews, 12(1): $147-179$ 
[10]. Huang, S.Y., Tang, R.N. and Chen, S.Y. 2003 Coagulase-negative staphylococcal bacteremia in critically ill children: risk factors and antimicrobial susceptibility. J Microbiol Immnol Infect. 36: 51-55

[11]. Khadri, H. and Alzohairy, M. 2010. Prevalence and antibiotic susceptibility pattern of methicillin-resistant and coagulase-negative staphylococci in a tertiary care hospital in India. Int. J. Med. Med. Sci. 2(4): 116-120

[12]. Koksal F.,Yasar, H. and Samasti, M. 2009. Antibiotic resistance patterns of coagulase-negative staphylococcus strains isolated from blood cultures of septicemic patients in Turkey. Microbiological Research 164:404-410

[13]. Kothavade R.J.,Kura M.M., and Panthaki, M.H. 2014. Candida tropicalis, its prevalence, pathogenicity and increasing resistance to fluconazole. Journal of Medical Microbiology. 5(2): 35-39

[14]. Malnick, S., Bardenstein, R., Huszar, M., Gabbay, J and Borkow, G. 2008. Pyjamas and sheets as a potential source of nosocomial pathogens. Journal of Hospital Infection; 70:89-92.

[15]. Muthaini, Y.M., Matiru V.N. and Bii, C. 2010. Potential second hand clothes and the effectiveness of disinfection methods. Kenyan Journal of Microbiology. 1: 1-19

[16]. National Committee for Clinical Laboratory Standards 1990. Approved standard M7-A2. Methods for dilution antimicrobial susceptibility tests for bacteria that grow aerobically. $2^{\text {nd }}$ Ed. Villanova.

[17]. Neely AN and Maley MP. 2000. Survival of enterococci and staphylococci on hospital fabrics and plastic. Journal of Clinical Microbiology; 38:724-6.

[18]. Neely, A. and Orloff, M. 2001. Survival of Some Medically Important Fungi on Hospital Fabrics and Plastics. Journal of Clinical Microbiology.39: 3360-3361

[19]. Nester, E.W., Anderson, G.D., Roberts E.C., Pearsall, N.N and Nester,M.T 2004. A Human Perspective Microbiology,4th Edition pp 535-645

[20]. Nkang, A.O. Okonko, I.O., Mejeha, O.K, Adewale O.G, Udeze, A.O, Fowotade, A., Fajobi,E. A., Adedeji, A.o and Babalola, E.T. 2009. Assessment of antibiotics susceptibility profiles of some selected clinical isolates from laboratories in Nigeria. J. Microbiol. Antimicrob. 1(2): 19-26

[21]. Pilonetto M, Rosa EA, Brofman PR, Baggio D, Calvário F, Schelp C, Nascimento A and Messias-Reason I. 2004 Hospital gowns as a vehicle for bacterial dissemination in an intensive care unit. Brazilian Journal of Infectious Diseases. 8: 206-10.

[22]. Sattler, C. and Armando, C. 2004. Coagulase Positive Staphylococcal Infections (Staphylococcus aureus), In: Ralph D. Feign (Editor), Textbook of Paediatric infectious diseases, 5th Edition, Saunders publishers, pp. 1099-1123.

[23]. Shiomori T, Miyamoto H, Makishima K, Yoshida M, Fujiyoshi T, Udaka T, Inaba T and Hiraki N. 2002 Evaluation of bed makingrelated airborne and surface methicillin resistant Staphylococcus aureus contamination. Journal of Hospital Infection; 50:30-5.

[24]. Tekalign, K. and Bacha, K. 2013. Prevalence and antibiotic susceptibility pattern of methicillin resistant Staphylococcus aureus among primary school children and pioneers in Jimma town, South West Ethiopia. Annals of Clinical Microbiology and Antimicrobials. 12: 11

[25]. Trillis, F., Eckstein, EC, Budavich, R, Pultz M J and Donskey CJ. 2008. Contamination of hospital curtains with healthcareassociated pathogens. Infection Control and Hospital Epidemiology 2008;29: 1074-6.

[26]. Wilkoff, B., Turabelidze, G., Lin, M., Dodson, D., Gladbach, S., and Zhu, BP. 2006. Personal hygiene and methicillin-resistant Staphylococcus aureus infection. Emerging Infectious Diseases; 12: 422-427.

[27]. Winn, W.C., Allen, S.D., Janda, W.M., Koneman, E.W., Procop, G.W., Schreckenberger, P.C., Woods, G.L. 2006. Koneman's Color Atlas and Textbook of Diagnostic Microbiology. 6th Ed. Philadelphia: PP 255

[28]. Wirth, F and Goldani Z.L 2012. Epidermiology of Rhodotorula, an emergin pathogen. Interdisciplinary perspective on infectious disease. 20(12): 7-15 